\title{
Genes and enzymes of the acetyl cycle of arginine biosynthesis in Corynebacterium glutamicum: enzyme evolution in the early steps of the arginine pathway
}

\author{
Vehary Sakanyan, ${ }^{1}$ Pavel Petrosyan, ${ }^{2}$ Michèle Lecocq, ${ }^{1}$ Anne Boyen, ${ }^{3,4}$ \\ Christiane Legrain, ${ }^{5}$ Marc Demarez, ${ }^{5}$ Jean-Noël Hallet ${ }^{1}$ and \\ Nicolas Glansdorff $3,4,5$
}

Author for correspondence: Vehary Sakanyan. Tel: +33 40373065. Fax: +3340292042.

\footnotetext{
1 Laboratoire de Biotechnologie, Faculté des Sciences et des Techniques, Université de Nantes, 2, rue de la Houssinière, F-44072 Nantes Cedex 03, France

2 Pharmagen, Knunyants Street 4, Yerevan 375010, Republic of Armenia

3,4,5 Microbiologie, Vrije Universiteit Brussel 3 , Vlaams Interuniversitair Instituut voor Biotechnologie4, Research Institute, CERIA-COOVI5, 1 avenue Emile Gryson, B-1070 Brussels, Belgium
}

\begin{abstract}
A cluster of arginine biosynthetic genes of Corynebacterium glutamicum ATCC 13032, comprising argJ, argB and argD as well as part of argC and argf, has been cloned by heterologous complementation of an Escherichia coli argE mutant. The gene order has been established as argCJBDF by sequencing the entire $4.4 \mathrm{~kb}$ cloned DNA fragment. The $C$. glutamicum argB gene can be transcribed in $E$. coli cells from an internal promoter located in the coding part of the preceding argJ gene, whereas transcription of the argJ gene appears vector-dependent. Expression of the corynebacterial arg $B$ gene is repressed by arginine in the native host but not in recombinant $E$. coli cells. Feedback inhibition of the corresponding $\boldsymbol{N}$-acetylglutamate kinase activity was observed both in cell extracts of $C$. glutamicum and in recombinant $E$. coli argB auxotrophic strains. Extracts of $E$. coli cells carrying cloned corynebacterial DNA display an ornithine acetyltransferase activity (encoded by argل) which alleviates the acetylornithinase (encoded by $\arg E$ ) deficiency of the enterobacterial host. In contrast to Bacillus stearothermophilus ornithine acetyltransferase which also exhibits acetylglutamate synthase activity, $C$. glutamicum ornithine acetyltransferase appears monofunctional. ArgA and ArgB proteins from different sources share highly significant similarities. The evolutionary implications of these data are discussed.
\end{abstract}

Keywords: Corynebacterium glutamicum, $\arg C J B D F$ sequence, ornithine acetyltransferase, $N$-acetylglutamate kinase, regulation

\section{INTRODUCTION}

Arginine biosynthesis sets off with the acetylation of the amino group of glutamate (Fig.1), mediated by $N$ acetylglutamate synthase (acetylCoA:L-glutamate $N$ acetyltransferase; EC 2.3.1.1; the $\arg A$ gene product). This acetylation prevents spontaneous cyclization and hence proline formation during the subsequent modifications of the 5-carboxyl group. Two strategies have evolved for the ulterior removal of the acetyl group. In the so-called linear pathway operative in Enterobacteriaceae and in the archaeon Sulfolobus solfataricus acetylornithinase $\left(N^{2}\right.$-acetyl-L-ornithine amidohydrolase; EC 3.5.1.16; the $\arg E$ gene product) catalyses the hydrolysis of $N$ -

The EMBL accession number for the sequence reported in this paper is X86157. acetylornithine into the arginine precursor ornithine and acetate (Cunin et al., 1986; Van de Casteele et al., 1990). All other prokaryotes investigated up to now, including methanogenic archaea (Meile \& Leisinger, 1984; Van de Casteele et al., 1990), Neisseria gonorrboeae (Shinners \& Catlin, 1978), members of the genus Bacillus (Sakanyan et al., 1992) and the eukaryotic microbes (Davis, 1986) use the more economical cyclic pathway that was first brought to light in Micrococcus glutamicus (Udaka \& Kinoshita, 1958 ), in which the acetyl group is recycled with generation of acetylglutamate. The transacetylation between acetylornithine and glutamate is mediated by the $\arg J$ gene product, ornithine acetyltransferase $\left(\mathrm{N}^{2}\right.$ acetyl-L-ornithine: L-glutamate $N$-acetyltransferase; EC 2.3.1.35). In organisms depending on the cyclic pathway, $N$-acetylglutamate synthase therefore fulfills an anaplerotic function. 


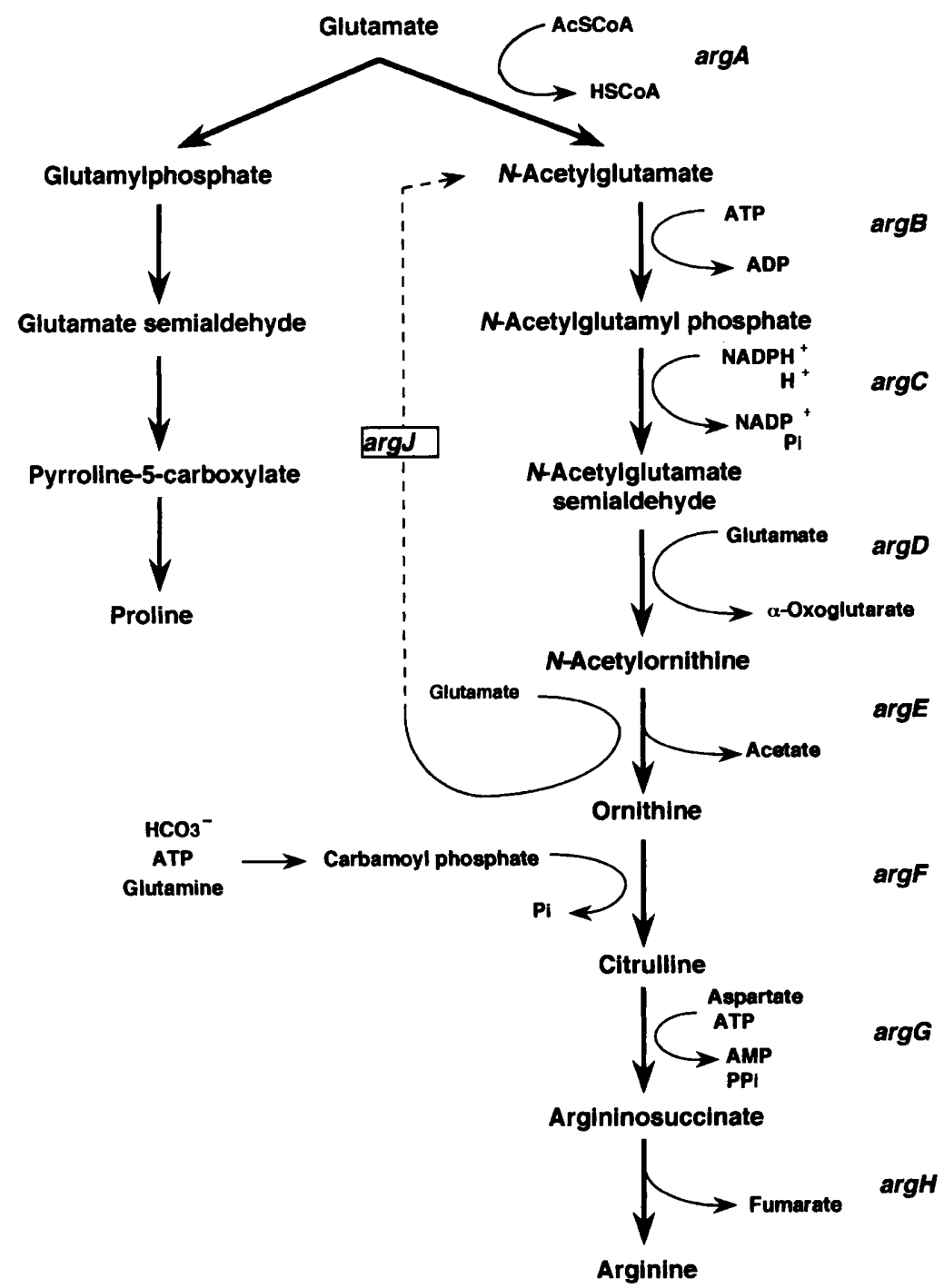

Fig. 1. Arginine biosynthesis and its relationship to the proline pathway. The dashed line indicates the acetyl group recycling by the argJ-encoded enzyme as an alternative to deacetylation by the $\arg E$ gene product.

Complementation experiments with N. gonorrboeae (Picard \& Dillon, 1989; Martin \& Mulks, 1992) and Bacillus stearothermophilus (Sakanyan et al., 1990) revealed that one small DNA fragment of these organisms could complement both $\arg A$ and $\arg E$ auxotrophs in E. coli. The responsible genes have since been sequenced and sufficient genetic (Martin \& Mulks, 1992; Sakanyan et al., 1992) and enzymic (Sakanyan et al., 1993a) data have been accumulated to prove that these organisms possess a bifunctional argJ-encoded product capable of using both the acetyl group of $N$-acetylornithine and that of acetylCoA to acetylate glutamate. It appears that Bacillus subtilis also harbours a bifunctional acetyltransferase (O'Reilly \& Devine, 1994).

Although the $\arg J$ gene by itself would thus be able to assure both the first and the fifth steps of arginine biosynthesis in these organisms, there is genetic evidence for the existence of an independent functional $\arg A$ gene in N. gonorrhoeae (Picard \& Dillon, 1989; Martin \& Mulks, 1992) and enzyme data for B. stearothermophilus point in the same direction (Sakanyan et al., 1992). In
Pseudomonas aeruginosa, however, the synthase and transacetylase activities can be separated by gel filtration (Haas et al., 1972). Moreover, $\arg A$ mutants have been isolated which display a normal acetyltransferase but no synthase activity and hence an arginineless phenotype. It has been shown that the synthase enzymes of $P$. aeruginosa (Haas $e t$ al., 1972; Haas \& Leisinger, 1974) and Saccharomyces cerevisiae (Wipf \& Leisinger, 1979) lack ornithine acetyltransferase activity; the properties of the ornithine acetyltransferases were not studied in detail. The data for $P$. aeruginosa therefore suggest the existence of a monofunctional ornithine acetyltransferase in this organism. Similarly, the cloned Streptomyces coelicolor ornithine acetyltransferase gene complements $E$. coli argE but not $\arg A$ mutants (Hindle et al., 1994).

In some micro-organisms the metabolic flow through the acetyl cycle is controlled by arginine-mediated feedback inhibition of the second biosynthetic step, catalysed by $\mathrm{N}$-acetylglutamate kinase (ATP: $N$-acetyl-L-glutamate 5phosphotransferase; EC 2.7.2.8; Udaka, 1966; Hoare \& Hoare, 1966; Haas \& Leisinger, 1975; Meile \& Leisinger, 
Table 1. Bacterial strains and plasmids used in this study

\begin{tabular}{|c|c|c|}
\hline Strain/plasmid & Relevant genotype/phenotype & Reference/source \\
\hline \multicolumn{3}{|l|}{ E. coli $\mathrm{K} 12$} \\
\hline JM109 & $\begin{array}{l}\mathrm{e}^{14^{-}}\left(\mathrm{McrA}^{-}\right) \operatorname{rec} A 1 \text { end } A 1 \text { gyr } A 96 \text { thi-1 } \\
\text { bsdR } 17 \text { sup E44 rel } A 1 \Delta(\text { lac-pro } A B) \\
{\left[\mathrm{F}^{\prime} \text { traD36 pro } A B \text { lac } I^{\mathrm{q}} Z \Delta \mathrm{M} 15\right]}\end{array}$ & Yanisch-Perron et al. (1985) \\
\hline $\mathrm{XA4}$ & $\mathrm{F}^{-} \arg A \operatorname{nal} A \lambda^{-} \lambda^{\mathrm{s}} b s d \mathrm{R}$ & Mountain et al. (1984) \\
\hline $\mathrm{XB} 25$ & $\mathrm{~F}^{-} \operatorname{argB}$ nal $A \lambda^{-} \lambda^{\mathrm{s}} b s d \mathrm{R}$ & Mountain et al. (1984) \\
\hline $\mathrm{XC} 33$ & $\mathrm{~F}^{-} \arg C$ nal $A \operatorname{rpoB} \lambda^{+} h s d \mathrm{R}$ & Mountain et al. (1984) \\
\hline PT2 & $\mathrm{F}^{-} \arg D$ pro $A B$ bis ilv $A$ metB $\operatorname{rps} L$ & Mountain et al. (1984) \\
\hline $\mathrm{XF}$ & $\begin{array}{l}\mathrm{F}^{-} \Delta 101(\text { pro } A B-a r g F-l a c) \text { argI thi supE } \\
\lambda^{-} \lambda^{\mathrm{s}} b s d \mathrm{R} \text { bsdM }\end{array}$ & Mountain et al. (1984) \\
\hline XG31 & Hfr $\arg G$ bis $r p o B \operatorname{rps} L \lambda^{-} \lambda^{\mathrm{s}} b s d \mathrm{R}$ & Mountain et al. (1984) \\
\hline $\mathrm{X} 190$ & $\begin{array}{l}\mathrm{Hfr}(\mathrm{P} 4 \mathrm{X}) \operatorname{car} A \text { met } B \text { thr } \lambda^{+} q j j 202:: \operatorname{Tn} 10 \\
b s d \mathrm{R}\end{array}$ & Mountain et al. (1984) \\
\hline XJEF8 & $\begin{array}{l}\mathrm{Hfr}(\mathbf{P} 4 \mathrm{X}) \operatorname{carB} \text { metB tbr } \lambda^{+} q j j 202:: \operatorname{Tn} 10 \\
\quad b s d \mathrm{R}\end{array}$ & Mountain et al. (1984) \\
\hline XS1D2R & $\mathrm{F}^{-} \Delta(p p c-a r g E) n a l A \operatorname{rpoB} \lambda^{-} b s d \mathrm{R} \operatorname{rec} A$ & Sakanyan et al. (1992) \\
\hline $\mathrm{XA} 4 \arg E$ & As XA4, but $\operatorname{argE} 86:: \operatorname{Tn} 10$ & Sakanyan et al. (1992) \\
\hline $\begin{array}{l}\text { C. glutamicum } \\
\text { ATCC } 13032\end{array}$ & Wild-type & $\begin{array}{l}\text { Collection of Industrial } \\
\text { Microorganisms, Moscow, } \\
\text { Russia }\end{array}$ \\
\hline \multicolumn{3}{|l|}{ Plasmids } \\
\hline pBR327 & $A p^{r} T c^{r}$ & Bolivar (1978) \\
\hline pUC9 & $A p^{r}$ lac $Z$ & Vieira \& Messing (1984) \\
\hline pUC18 & Ap $p^{r}$ lac $Z$ & Yanisch-Perron et al. (1985) \\
\hline pGA46 & $\mathrm{Ap}^{\mathrm{r}} \mathrm{Cm}^{\mathrm{r}}$ & An \& Friesen (1979) \\
\hline pBluescript II KS(+) & $\mathrm{Ap}^{\mathrm{r}} \operatorname{lac} Z$ & Stratagene \\
\hline pPP2 & pBR327-derivative, $A p^{r} T^{r}$ & This work \\
\hline
\end{tabular}

1984). However, in B. stearothermophilus no noticeable inhibition of $N$-acetylglutamate kinase by either ornithine or arginine could be detected. Instead, the target for inhibition was found to be the bifunctional argJ (and possibly the $\arg A$ ) gene product : both $N$-acetylglutamate synthase and ornithine acetyltransferase activities were strongly inhibited by ornithine. Arginine, however, did not affect either activity (Sakanyan et al., 1993a). Consequently, in this organism the metabolic intermediate ornithine, rather than the end-product arginine appears to be critical for controlling metabolite conversions in the arginine acetyl cycle.

In order to clarify the organization and the regulation of the cyclic acetylation pathway a more extensive study was desirable. We have undertaken the genetic and enzymic examination of the pathway in Corynebacterium glutamicum, formerly Micrococcus glutamicus (Jones \& Collins, 1986), a Gram-positive mesophilic bacterium. Indigenous nonpathogenic corynebacteria, particularly representatives of Corynebacterium and Brevibacterium, synthesize and excrete large quantities of glutamic acid in broth cultures (Shiio $e t$ al., 1962). Genetically improved strains have therefore long been exploited for the industrial production of arginine and proline (Kinoshita \& Nahayama, 1978), but the underlying genetics has not been studied extensively. The data reported below provide new information on the acetyl cycle in this organism.

\section{METHODS}

Bacterial strains and plasmids. The strains and plasmids used in this work are listed in Table 1.

Media and growth conditions. C. glutamicum cells were grown on a rotary shaker $\left(150\right.$ r.p.m.) at $30^{\circ} \mathrm{C}$ in Luria-Bertani (LB) medium (Sambrook et al., 1989) or in a synthetic medium described by Bröer et al. (1993). LB as well as the synthetic M9 medium (Miller, 1972) were used for E. coli K12 strains. M9 was supplemented with all auxotrophic requirements other than arginine for complementation analysis of arg mutants by $C$. glutamicum DNA. E. coli cells were grown at $37^{\circ} \mathrm{C}$, except for complementation tests which were performed at $30^{\circ} \mathrm{C}$. Antibiotics were added at a final concentration of $50 \mu \mathrm{g} \mathrm{ml}^{-1}$ for ampicillin, $30 \mu \mathrm{g} \mathrm{ml}^{-1}$ for chloramphenicol and $25 \mu \mathrm{g} \mathrm{ml}^{-1}$ for tetracycline.

DNA manipulation and transformation. Chromosomal DNA of C. glutamicum was isolated as described by Eikmanns $e t$ al. (1991). Plasmid DNA from E. coli was isolated by the alkaline lysis method of Birnboim \& Doly (1979) or with Qiagen-tip columns (QIAGEN). Agarose gel electrophoresis, DNA restriction, alkaline phosphatase treatment and ligation were performed following classical protocols (Sambrook et al., 1989). $E$. coli strains were transformed following the $\mathrm{CaCl}_{2}$ procedure (Sambrook et al., 1989) or by electroporation with the geneZapper 450-2500 apparatus (International Biotechnologies) according to the manufacturer's recommendations.

DNA sequencing and sequence analysis. Prior to sequencing subfragments were cloned into the pBluescript II $\mathrm{KS}(+)$ vector. 
ExollI-generated unidirectional deletions were obtained according to the method of Sambrook et al. (1989). Sequencing was performed by the dideoxynucleotide chain-termination method (Sanger et al., 1977) using sequenase Quick-denaturate plasmid sequencing kits (USB) and $\left[\alpha^{35}\right.$ S ]dATP (Amersham). Either universal or reverse primers or synthetic 17-mer oligonucleotides (provided by D. Gigot, Research Institute, CERIACOOVI, Brussels, and by Eurogentec) were used. Sequence ladders were resolved on gels containing $6 \%(\mathrm{w} / \mathrm{v})$ polyacrylamide with taurine. The sequence data were compiled, analysed and aligned with various programs from the MacVector package (International Biotechnologies), as well as with Clustal v (Higgins \& Sharp, 1988) and FASTA (Pearson \& Lipman, 1988). The Swiss-Prot database (EMBL) was consulted for protein sequences.

Enzyme assays. E. coli and C. glutamicum cells were grown in synthetic media, harvested by centrifugation during the exponential phase, washed in $0.9 \%(\mathrm{w} / \mathrm{v}) \mathrm{NaCl}$ and resuspended in $10 \mathrm{mM}$ potassium phosphate buffer ( $\mathrm{pH} 6.5$ ) containing $15 \%$ (v/v) glycerol, $1 \mathrm{mM}$ EDT A, $1 \mathrm{mM} \mathrm{DTT}$ and $2 \mathrm{mM}$ PMSF for $N$-acetylglutamate synthase and ornithine acetyltransferase assays, or in $25 \mathrm{mM}$ Tris/ $\mathrm{HCl}$ buffer ( $\mathrm{pH} 7 \cdot 5)$ for other assays. Cells were disrupted by sonication and the resulting crude extract was centrifuged $(20000 \mathrm{~g}, 15 \mathrm{~min})$. All these treatments were performed at temperatures below $10{ }^{\circ} \mathrm{C}$. Enzyme assays were carried out at $30^{\circ} \mathrm{C}$. For inhibition experiments the crude cell extracts were passed through Sephadex G-25 columns equilibrated with extraction buffer.

$N$-Acetylglutamate synthase and ornithine acetyltransferase were assayed as described in Van de Casteele et al. (1990), except that $15 \%(\mathrm{v} / \mathrm{v})$ glycerol, $10 \mathrm{mM} \mathrm{MgCl}_{2}$, and $7 \mathrm{mM}$ aminooxyacetic acid were added to the incubation mixture. $N$ Acetylglutamate kinase was measured by the ferric chloride method (Udaka, 1966) as described previously by Van de Casteele et al. (1990). Acetylornithinase was measured by the method of Vogel \& McLellan (1970) as described in Sakanyan et al. (1993c).

\section{RESULTS AND DISCUSSION}

\section{Cloning of C. glutamicum arginine biosynthetic genes and their expression in $E$. coli mutants}

Cloning of the C. glutamicum argJ gene was undertaken by selecting for heterologous complementation of $\arg E$ deficiency in E. coli as obtained with $N$. gonorrboeae and $B$. stearothermophilus DNA (Picard \& Dilon, 1989; Sakanyan et al., 1990). An EcoRI-digest of C. glutamicum ATCC 13032 DNA was ligated into EcoRI-cleaved vector pBR327. The resulting plasmids were transformed into E. coli K12 XS1D2R and arginine prototrophs were selected on synthetic medium supplemented with succinate, ampicillin and tetracycline. The recombinant pPP2 plasmid which carries a single $4.4 \mathrm{~kb}$ EcoRI insert was isolated from the selected transformants. Its restriction map derived from single- and double digest data with several enzymes is shown in Fig. 2.

Ampicillin-resistant pPP2 transformants of various arginine auxotrophic E. coli $\mathrm{K} 12$ mutants were screened for complementation by replica plating on synthetic medium without arginine. Apart from the argE-deficient strain mentioned above, pPP2 complemented argB mutant $\mathrm{XB} 25$. Of particular interest to our study is its failure to complement $\arg A$-deficient strains XA4 and its derivative
XA4argE. Enzyme assays summarized in Table 2 confirmed these results. $N$-Acetylglutamate kinase and ornithine acetyltransferase activities measured in cell extracts of E. coli $\mathrm{K} 12 \mathrm{XB} 25(\mathrm{pPP} 2)$ and $E$. coli $\mathrm{XA4}(\mathrm{pPP} 2)$, respectively, were raised significantly above the background level of the plasmidless strain. Acetylglutamate synthase and acetylornithinase activities, in contrast, remained undetectable in extracts of $E$. coli $\mathrm{K} 12$ $\mathrm{XA} 4(\mathrm{pPP} 2)$ and E. coli K12 XS1D2R(pPP2). From these results it can be inferred that the cloned fragment harbours the structural C. glutamicum argB and $\arg J$ genes and that the $\arg J$-encoded ornithine acetyltransferase relieves the acetylornithinase deficiency of the E. coli argE mutant by heterologous complementation.

Since the native C. glutamicum ATCC 13032 displays $N$-acetylglutamate synthase activity (see Table 2) it can be assumed that the corresponding $\arg A$ gene is not located on the pPP2 plasmid unless it is non-functional in E. coli cells. Consequently, the cloned $C$. glutamicum arg $J$ gene appears to encode a monofunctional enzyme capable of transacetylating the acetyl group of $\mathrm{N}$-acetylornithine (ornithine acetyltransferase activity), but not that of acetylCoA ( $N$-acetylglutamate synthase activity) to glutamate.

\section{Sequence analysis}

The sequence of the entire $4.4 \mathrm{~kb}$ insert of $C$. glutamicum DNA in pPP2 has been established on both strands using ExolII-generated $200-300 \mathrm{bp}$ deletions in a subcloned $1.9 \mathrm{~kb}$ HindIII-XboI fragment (plasmid pKS-1.9) and several other subcloned fragments. Analysis of the nucleotide sequence reveals five large ORFs (Fig. 3) oriented in the same way, those at the fragments' ends being truncated. The ORFs were numbered as indicated in Fig. 2. Comparison of the corresponding amino acid sequences with known arginine metabolic enzymes from various sources (see also below) shows that all of them correspond to arginine biosynthetic genes: truncated ORF1 matches the $\mathrm{C}$-terminal end of the $\arg C$-encoded polypeptide, ORF 2, ORF3 and ORF4 appear respectively homologous with the $\operatorname{argJ}-, B$ - and $D$-encoded enzymes and finally, the truncated ORF5 corresponds with the Nterminal region of the $\operatorname{argF}$ gene product. Putative RBSs can be found upstream of the proposed initiation codons of ORFs $2-5$ and are indicated in Fig. 3. The cloned $4 \cdot 4 \mathrm{~kb}$ insert therefore seems to contain an important part of a large arginine biosynthetic cluster as in B. subtilis (Mountain et al., 1986), N. gonorrboeae (Picard \& Dilon, 1989), B. stearothermopbilus (Sakanyan et al., 1990; Sakanyan et al., 1993a) and S. coelicolor (Hindle et al., 1994). A fairly large ORF6 oriented in the opposite direction showed no significant resemblance to any sequence as yet registered in the protein databases. Searching specifically for homology between C. glutamicum ORFs and the known acetylglutamate synthase sequences of $E$. coli (Brown $e t$ al., 1987), P. aeruginosa and Pseudomonas putida (Dharmsthiti \& Krishnapillai, 1993) and Neurospora crassa (Y. Yu \& R. L. Weiss, unpublished; EMBL accession number L35484) was negative, except for ORF3 which 


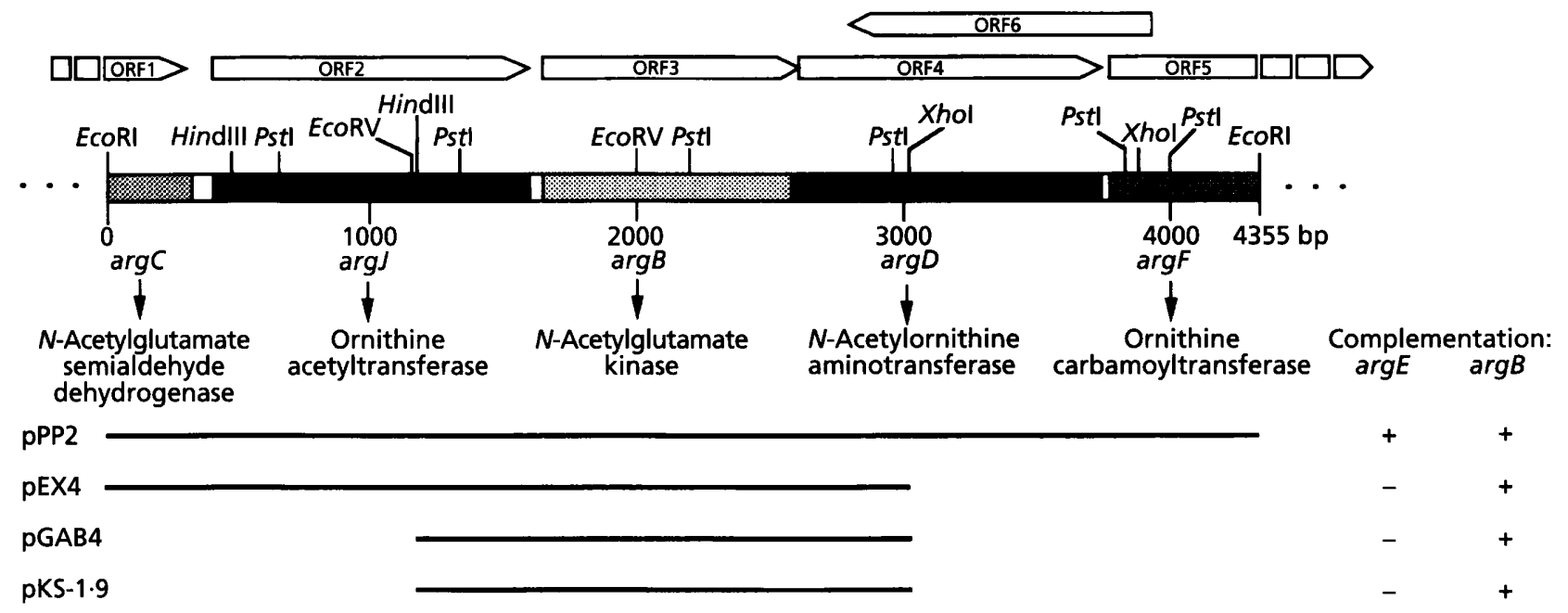

Fig. 2. Genetic and restriction maps of the $4.4 \mathrm{~kb}$ insert of $C$. g/utamicum DNA in pPP2. The arrowhead boxes show the localization and orientation of the ORFs. The corresponding genes and the encoded enzymes are indicated. Plasmid pEX4 was constructed by cloning the ECORI-Xhol fragment from pPP2 into EcoRI/Sall-digested pUC9, and plasmid pGAB4 was constructed by cloning the HindIII-Xhol fragment into HindIII/Sall-digested pGA46. These plasmids were used in complementation experiments with $E$. coli K12 XB25 and XS1D2R strains (results indicated to the right). The HindIII-Xhol fragment from PPP2 was also cloned into the HindIII/Sall sites of pUC18 and re-cloned after excision with HindIII and EcoRI (taking advantage of the polylinker site) into HindIII/EcoRI-digested pBluescript II KS(+), yielding plasmid pKS-1.9.

corresponds to the $\arg B$ gene. This homology between acetylglutamate synthase and acetylglutamate kinase is supported by the comparison of other $\arg A$ and $\arg B$ gene couples (Reith \& Munholland, 1993; see below).

According to a BESTFIT comparison, the C. glutamicum ArgJ sequence shares 36,35 and $39 \%$ identical amino acids with the ornithine acetyltransferases of $N$. gonorrboeae (Martin \& Mulks, 1992), B. subtilis (O'Reilly \& Devine, 1994) and B. stearothermopbilus (Sakanyan et al., 1993a), respectively. The CLUSTAL alignment shown in Fig. 4 indicates that the similarity covers the whole sequence, though the $C$. glutamicum polypeptide appears shorter than its bifunctional homologues by $11-12$ amino acids at the N-terminal end. Its predicted molecular mass is $39.8 \mathrm{kDa}$, approximately $3 \mathrm{kDa}$ less than for the other known bacterial ornithine acetyltransferases; it contains only $6.7 \%$ of basic amino acids which is substantially lower than the $10 \%$ found for the other ArgJ products.

A BESTFIT comparison shows that the $N$-acetylglutamate kinase polypeptide sequence of $C$. glutamicum shares approximately $42 \%$ identical amino acids with the $N$ acetylglutamate kinase of Porpbyra umbilicalis (Reith \& Munholland, 1993), 39\% with that of B. stearothermophilus (Sakanyan et al., 1993b), 35\% with that of B. subtilis (O'Reilly \& Devine 1994), 29\% with that of E. coli (Parsot $e$ t al., 1988), $25 \%$ with that of N. crassa (Gessert $e t$ al., 1994) and $23 \%$ with those of S. cerevisiae (Boonchird $e t$ al., 1991) and Schizosaccharomyces pombe (Van Huffel et al., 1992).

Sequence analysis indicates that the initiation codon of the C. glutamicum $\arg D$ gene is contiguous to the $\operatorname{argB}$ TAA termination codon, whereas an intergenic space is observed between the other corynebacterial arg genes of the cluster. The same tendency was observed in $B$. stearothermophilus (Sakanyan et al., 1993b) and B. subtilis (O'Reilly \& Devine, 1994), where the $\operatorname{argB}$ and $\arg D$ genes overlap for a few nucleotides and suggests translational coupling, while a relatively long intergenic space was found at the $\operatorname{argC} / \arg J$ and $\arg J / \operatorname{argB}$ transitions. A CLUSTAL alignment of the deduced ArgD polypeptide sequence with those of E. coli, B. subtilis and S. cerevisiae (data not shown) revealed 40, 42 and $36 \%$ identical amino acids, respectively.

The overall $\mathrm{G}+\mathrm{C}$ content of the $4.4 \mathrm{~kb}$ stretch of $C$. glutamicum DNA amounts to $54.6 \%$, which corresponds with the mean value for glutamic-acid-producing corynebacteria (Yamada \& Komagata, 1970). A remarkable feature in codon usage is the unexpectedly high appearance of the rare CGA arginine codon in the arg gene ( 4 out of 12 codons). Apart from that there is a relatively low occurrence of $\mathrm{G}+\mathrm{C}$ in the third position of the $\arg J$ codons: $51 \cdot 7 \%$ as compared to $59 \cdot 3$ and $64 \cdot 1 \%$ for the $\operatorname{argB}$ and $\arg D$ genes, respectively. There is no strong bias for corynebacterial 'preferred' codons (Malumbres et al., 1993) in either $\operatorname{argJ}, \operatorname{argB}$ or $\operatorname{argD}$; therefore a low-to-moderate expression might be expected.

\section{Evidence for a secondary promoter upstream of the $\arg B$ gene}

From the sequence analysis it appears that the pEX4 plasmid, constructed by subcloning the $3.1 \mathrm{~kb}$ EcoRIXboI fragment in EcoRI/SalI-cut pUC9 vector, should carry the whole of the structural information for both the 


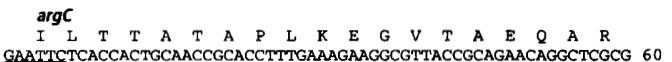
GAATCCTCACCACTGCAACCGCACCTTTGAAAGAAGGCGTTACCGCAGAACAGGCTCGCG 60 $\begin{array}{llllllllllllll}\text { CAGTATATGAGGAGTTCTATGCACAGGAAACCTTCGTGCATGTTCTTCCAGAAGGTGCAC } & 120\end{array}$ Q $P$ P Q AGCCACAAACCCAAGCAGTTCTTGGCTCCAACATGTGCCACGTGCAGGTAGAAATTGATG 180

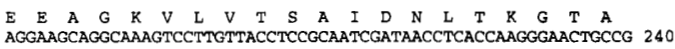
$G$ A A $V$ C Q C C M N L L S V V G F D GCGCCGCTGTTCAGTGCATGAACTTAAGCGTTGGTTTTGATGAGGCAGCAGGCCTGCCAC 300 $Q$
AGGTCGGCGTCGCACCTTAAAGTAGCGCCTTAAAGCGGCGCTTCAAACCAAGCGCCCTAA 360 $\begin{array}{llllll}\arg \\ M & A & E & K & G & \text { I }\end{array}$ CCAGCAAACACAACAAACACATCTAATTCAGTAGGAGTTCCACATGGCAGAAAAAGGCAT 420

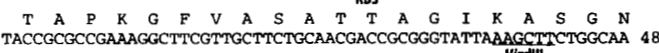
$\begin{array}{lllllllllllllllllllllll}\text { P } & D & M & A & L & V & V & N & Q & G & P & E & F & S & A & A & A & V & F & T\end{array}$ TCCTGACATGGCGTTGGTGGTTAACCAGGGTCCAGAGTTTTCCGCAGCGGCCGTGTTTAC 540 $\begin{array}{rrrrrrrrrrrrrrrrrrrr}R & N & R & V & F & A & A & P & V & K & V & S & R & E & N & V & A & D & G & Q \\ \text { ACGTAACCGAGTTTTCGCAGCGCCTGTGAAGGTGAGCCGAGAGAACGTTGCTGATGGCCA } & 600\end{array}$

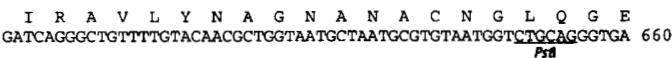

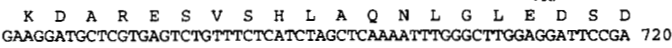

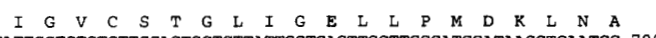
TATTGGTGTGTGTTCCACTGGTCTTATTGGTGAGTTGCTTCCGATGGATAAGCTCAATGC 780

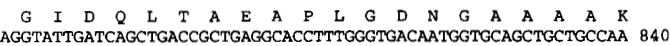
$\begin{array}{llllllllllllllllllll}A & I & M & T & T & D & T & V & D & K & E & T & V & V & F & A & D & G & W & T\end{array}$ GGCGATCATGACCACTGACACGGTGGATAAGGAAACCGTCGTGTTTGCTGATGGTTGGAC 900

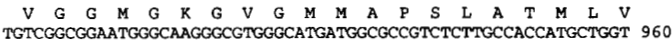

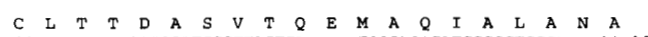
CTGCTTGACCACTGATGCATCCGTTACTCAGGAAATGGCTCAGATCGCGCTGGCTAATGC 1020 $\begin{array}{rllllllllllllllll}\text { T A } & \text { V V T T F } & \text { D } & \text { T } & \text { L } & \text { D } & \text { I } & \text { D } & G & \text { G } & \text { T } & \text { S } & \text { T } & \text { N } & \text { D } & T & \text { V } \\ \text { TACGGCCGTTACGTTTGACACCCTGGATATTGATGGATCAACCTCCACCAATGACACCGT } & 1080\end{array}$ $\begin{array}{cccccccccccccccccccc}\text { F } & \text { L } & \text { L } & \text { A } & \text { S } & \text { G } & \text { A } & \text { S } & \text { G } & \text { I } & \text { T } & \text { P } & \text { T } & \text { Q } & \text { D } & \text { E } & \text { L } & \text { N } & \text { D } & \text { A } \\ \text { GTTCCTGCTGGCATCTGGCGCTAGCGGAATCACCCCAACTCAGGATGAACTCAACGATGC } & 1140\end{array}$

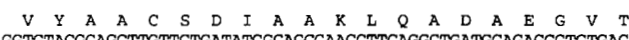
GGTGTACGCAGCTTGTTCTGATATCGCAGCGAAGCTTCAGGCTGATGCAGAGGGTGTGAC 1200

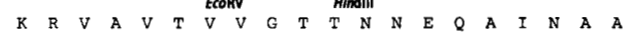
CAAGCGCGTTGCTGTGACAGTGGTGGGAACCACCAACAACGAGCAGGCGATTAATGCGGC 1260

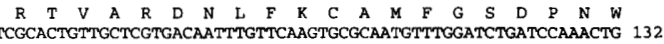
$\begin{array}{llllllllllllllllllll}G & R & V & L & A & A & V & G & M & A & D & A & D & M & E & P & E & K & I & S\end{array}$ GGGTCGCGTGTTIGGCTGCAGTCGGCATGGCTGATGCTGATATGGAACCAGAGAAGATTTC 1380

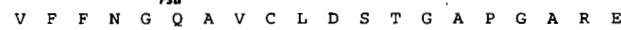

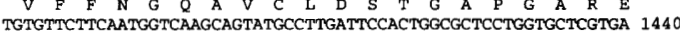
$\begin{array}{lllllllllllllllllllll}V & D & \text { L } & S & G & A & D & I & D & V & R & \text { I } & \text { D } & \text { L } & G & \text { T } & S & G & \text { E } & G\end{array}$ GGTGGATCTTTCCGGCGCTGACATTGATGTCCGAATTGATTTGGGCACCAGTGGGGAAGG 1500

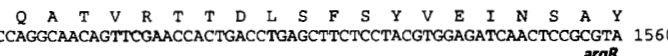
$s$ s $\underset{\mathrm{M}}{\arg \mathrm{N}}$ CAGCTCTTAAAAAGAAACAGCACTCCAACTAACAAGCAGGGAAAAGGGCACAGGCATGAA 1620

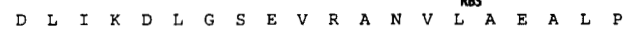
TGACTTGATCAAAGATTTAGGCTCTGAGGTGCGCGCAAATGTCCTCGCTGAGGCGTTGCC 1680

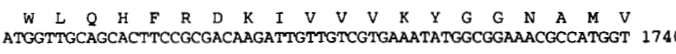
$\begin{array}{lllllllllllllllllllllllllllll}D & D & D & L & K & A & A & F & A & A & D & M & V & F & \text { I. } & R & T & V & G & A\end{array}$ GGATGATGATCTCAACGCTGCTTMTCCTGCCGACATGGTCTTCTTGCGCACCGTGGGCGC 1800

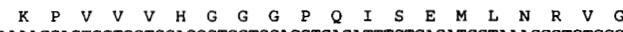
AAAACCAGTGGTGGTGCACGGTGGTGGACCTCAGATTTCTGAGATGCTAAACCGTGTGGG 1860

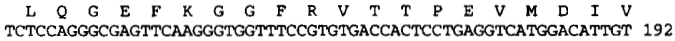

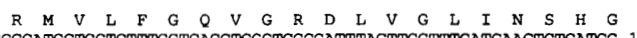
GCGCATGGTGCTCTTTGGTCAGGTCGGTCGCGATTTAGTTGGTPTGATCAACTCTCATG 1980 $\begin{array}{cccccccccccccccccccc}\text { P } & \text { Y } & \text { A } & \text { V } & G & \text { T } & \text { S } & G & \text { E } & \text { D } & \text { A } & G & \text { L } & \text { F } & \text { T } & \text { A } & Q & \text { K } & \text { R } & \text { M } \\ \text { CCCTTACGCTGTGGGAACCTCCGGTGAGGATGCGGCCTGTTTACCGCGCAGAAGCGCAT } & 2040\end{array}$ $\begin{array}{llllllllllllllllllll}V & N & I & D & G & V & P & T & D & I & G & L & V & G & D & I & I & N & V & D\end{array}$ GGTCAACATCGATGGCGTACCCACTGATATTGGTTTGGTCGGAGACATCATTAATGTCGA 2100

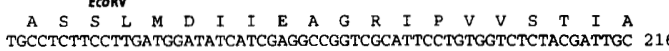

P G G E D D G $Q 0$ I TCCAGGCGAAGACGGCCAGATTTACAACATTAACGCCGATACCGCAGCAGGTGCTTTTGGC 2220 $\underset{\text { TGCAGCGATTGGTGCAGAACGCCTGCTGGTTCTCACCAATGTGGAAGGTCTGTACACCGA }}{\text { A }} \mathbf{A}$ I 2280 TGCAGCGATTGGTGCAGAACGCCTGCTGGTTCTCACCAATGTGGAAGGTCTGTACACCGA 2280 TTGGCCTGATAAGAGCTCACTGGTGTCCAAGATCAAGGCCACCGAGCTGGAGGCCATTCT 2340

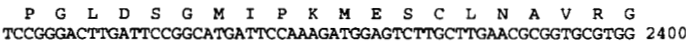

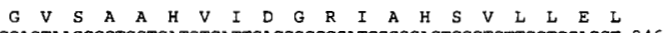

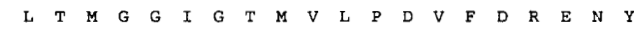
TTTGACCATGGGTGGAATTGGCACGATGGTGCTGCCGGATGTTTTTGATCGGGAGAATTA 2520

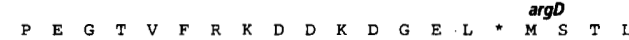
TCCTGAAGGCACCGTTTTTAGAAAAGACGACAAGGATGGGGAACTGTAAATGAGCACGCT 2580

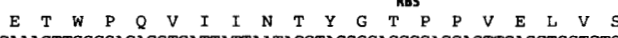
GGAAACTTGGCCACAGGTCATTATTAATACGTACGGCACCCCACCAGTTGAGCTGGTGTC 2640 $\begin{array}{lllllllllllllllllllllllllll}G & K & G & A & \text { T } & \text { V } & \text { T } & \text { D } & \text { D } & Q & G & \text { N } & \text { V } & \text { Y } & \text { I } & \text { D } & \text { L } & \text { L } & \text { A } & \text { G } & & \end{array}$

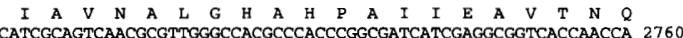

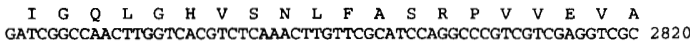

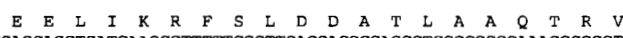
CGAGGAGCTCATCAAGCGTTTTTCGCTYGACGACGCCACCCTCGCCGCGCAAACCCGGG 2880

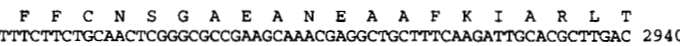
$\begin{array}{llllllllllllllllllll}G & R & S & R & I & L & A & A & V & H & G & F & H & G & R & T & M & G & S & L\end{array}$ TGGTCGTTCCCGGATTCTGGCTGCAGTTCATGGTTTCCACGGCCGCACCATGGGTTCCCT 3000 $\begin{array}{llllllllllllllllllll}\text { A } & L & T & G & Q & P & D & \text { PSA } & R & E & \text { A } & F & L & P & M & P & S & G & V & E\end{array}$ CGCGCTGACTGGCCAGCCAGACAAGCGTGAAGCGTTCCTGCCAATGCCAAGCGGTGTGGA 3060 $\begin{array}{lllllllllllllllllllll}F & Y & P & Y & G & D & T & D & Y & L & R & K & M & V & E & T & N & P & T & D\end{array}$ $\begin{array}{lllllllllllllllllllllllllllll}V & A & A & I & F & L & E & P & I & Q & G & E & T & G & V & V & P & A & P & E\end{array}$ TGTGGCTGCTATCTTCCTCGAGCCAATCCAGGGTGAAACGGGCGTTGTTCCAGCACCTGA 3180 $\begin{array}{lllllllllllllllllllllllll}G & F & L & K & A & V & R & E & L & C & D & E & Y & G & I & L & M & I & T & D\end{array}$

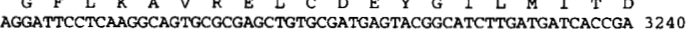
$\begin{array}{rllllllllllllllllll}\text { E } & V & Q & T & G & V & G & R & T & G & D & F & F & A & \text { H } & Q & H & D & G\end{array}$

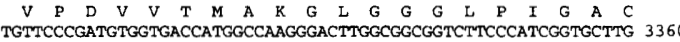

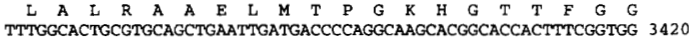

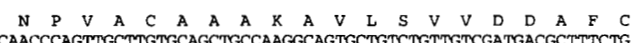
CAACCCAGTTGCTTGTGCAGCTGCCAAGGCAGTGCTGTCTGTTGTCGATGACGCTTTCTG 3480

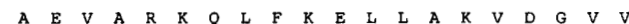
GCAGAAGTTGCCCGCAAGCAGCTGTTCAAGGAACTTCTTGCCAAGGTTGACGGCGTTGT 3540

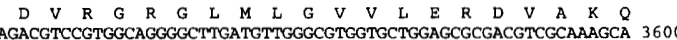

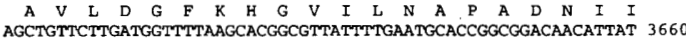

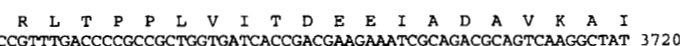
CCGTTTGACCCCGCCGCTGGTGATCACCGACGAAGAAATCGCAGACGCAGTCAAGGCT TGCCGAGACAATCGCATAAAGGACTCAAACTTATGACTTCACAACCACAGGTTCGCCATT 3780

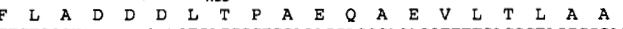
TTCTGGCTGATGATGATCTCACCCCTGCAGAGCAGGCAGAGGTTTTGACCCTAGCCGCAA 3840 $\begin{array}{llllllllllllllllllll}K & L & K & A & A & P & F & S & E & R & P & L & E & G & P & K & S & V & A & V\end{array}$ AGCTCAAGGCAGCGCCGTTTTICGGAGCGTCCACTCGAGGGACCAAAGTCCGTTGCAGTTC 3900 $\begin{array}{llllllllllllllllllll}L & F & D & K & T & S & T & R & T & R & F & S & F & D & A & G & I & A & H & L\end{array}$ TTTTTGATAAGACTTCAACTCGTACTCGCTTCTCCTTCGACGCGGGCATCGCTCATTTGG 3960

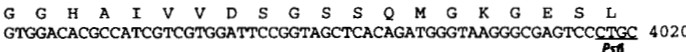

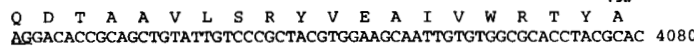
$\begin{array}{llllllllllllllllllll}H & S & N & F & \text { H } & \text { A } & M & \text { A } & \text { E } & \text { T } & S & \text { T } & \text { V } & \text { P } & \text { L } & V & N & S & L & S\end{array}$ ACAGCAATTTCCACGCCATGGCGGAGACGTCCACTGTGCCGCTGGTGAACTCCTTGTCCG 4140

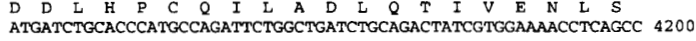

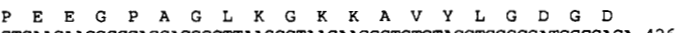
$\begin{array}{llllllllllllllllllll}N & N & M & A & N & S & Y & M & I & G & F & A & T & A & G & M & D & I & S & I\end{array}$ ACAACATGGCCAACTCCTACATGATTGGCTTTGCCACCGCGGGCATGGATATTTCCATCA 4320

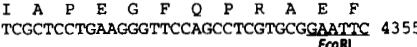

Fig. 3. For legend see facing page. 


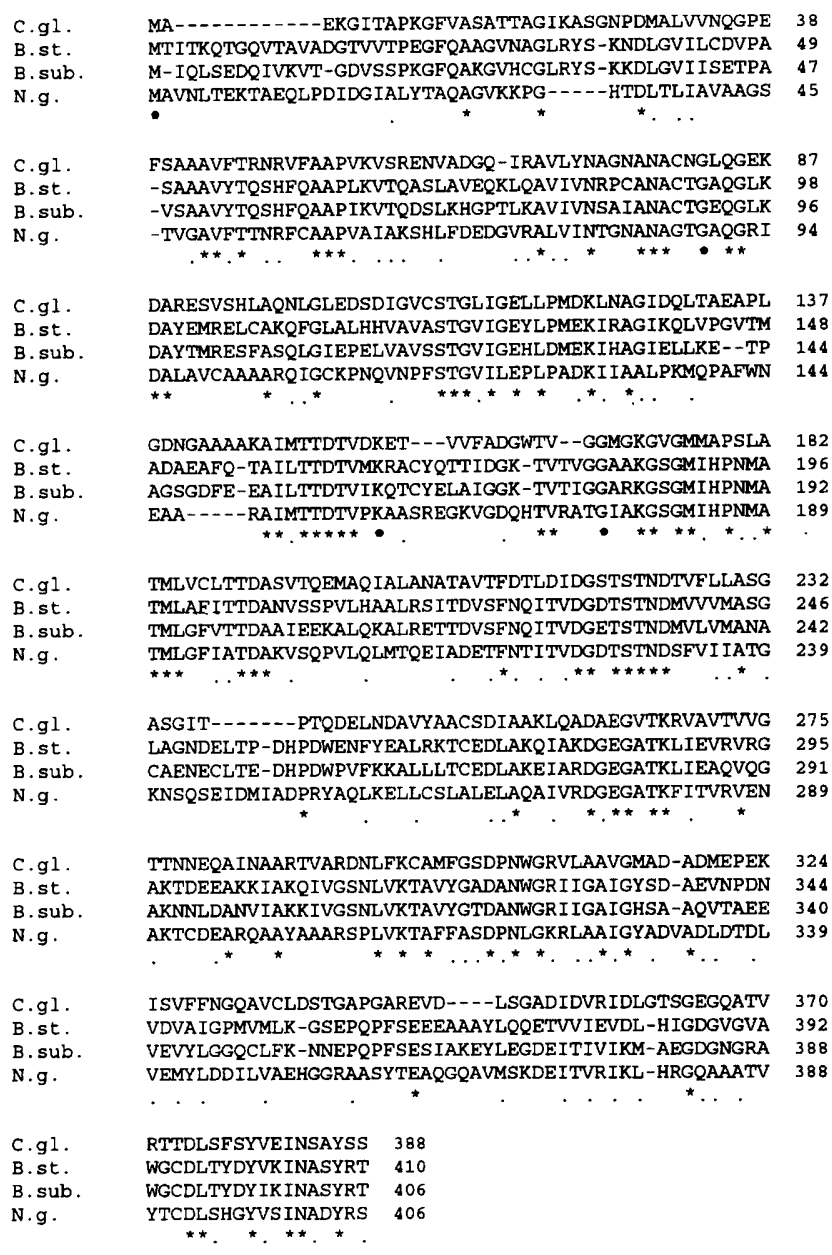

Fig. 4. Comparison of entire amino acid sequences of ornithine acetyltransferases by CLUSTAL V alignment. C.gl., C. glutamicum (this work); B.st., B. stearothermophilus (Sakanyan et al., 1993a); B.sub., B. subtilis (O'Reilly \& Devine, 1994); N.g., N. gonorrhoeae (Martin \& Mulks, 1992). Asterisks indicate that identical residues occur in all four polypeptides; dots show replacement by similar amino acids.

$\arg J$ and the $\operatorname{argB}$ genes (Fig. 2). Nevertheless, no E. coli K12 XS1D2R(pEX4) transformants could be selected on arginineless synthetic medium supplemented with ampicillin. Arginine prototrophic E. coli K12 $\mathrm{XB} 25(\mathrm{pEX} 4)$ transformants, however, were readily obtained.

The orientation of the $C$. glutamicum argJ gene, in opposition to the lac promoter-directed transcription in pEX4, is probably responsible for the contrasting argE complementation results obtained with $\mathrm{pPP} 2$ and $\mathrm{pEX} 4$. The ornithine acetyltransferase activity displayed by $\mathrm{pPP} 2$ harbouring E. coli strains would then result from some promoter located in the pBR327 vector itself.
Transcription of the C. glutamicum argB gene in E. coli, however, seems independent from an extraneous promoter, a result confirmed by the significant $N$ acetylglutamate kinase activity observed in the $E$. coli K12 XB25(pGAB4) strain (Table 2). The pGAB4 plasmid was constructed by inserting the $1.9 \mathrm{~kb} H$ HindIII-XhoI fragment (see Fig. 2) in HindIII/SalI double-digested promoter-probe vector pGA46. As no transcription can proceed from the pGA46 vector into the inserted DNA (An \& Frisen, 1979), it seems likely that in E. coli cells at least, transcription can be initiated at a promoter located between the HindIII site at $1172 \mathrm{nt}$ and the beginning of the structural $\operatorname{argB}$ gene of $C$. glutamicum. Evidence for the occurrence of a promoter site recognized by $E$. coli RNA polymerase preceding the $\arg B$ structural gene has been reported for B. stearothermophilus as well (Sakanyan et al., 1993b).

\section{Repression of enzyme formation and feedback inhibition by arginine}

$N$-Acetylglutamate synthase, $N$-acetylglutamate kinase and ornithine acetyltransferase activities were measured in extracts of $C$. glutamicum cells grown in the absence or in the presence of arginine (Table 2). The levels of $N$ acetylglutamate synthase and ornithine acetyltransferase were not affected by arginine addition. A fivefold repression of $\mathrm{N}$-acetylglutamate kinase synthesis was observed in the presence of arginine.

Inhibition of enzyme activity by arginine was tested for the three enzymes by adding L-arginine (concentration range $0.01-100 \mathrm{mM}$ ) to the reaction mixture of the enzyme assays described above. Arginine was found to inhibit $N$ acetylglutamate synthase and $N$-acetylglutamate kinase activities; the arginine concentrations for $50 \%$ inhibition were 40 and $2 \mathrm{mM}$, respectively. Feedback inhibition by arginine of corynebacterial $N$-acetylglutamate kinase has already been reported (Udaka, 1966). Inhibition by Larginine (more than $80 \%$ at $10 \mathrm{mM}$ arginine) could also be detected for $C$. glutamicum $N$-acetylglutamate kinase synthesized in $E$. coli $\mathrm{K} 12 \operatorname{argB}$ mutant cells carrying pPP2, pKS-1.9 or pGAB4. Whether $N$-acetylglutamate kinase inhibition actually plays a regulatory role in vivo remains to be established, since the apparent inhibition constant of arginine is high. One must, however, take into account that this value was determined with crude extracts and at saturating levels of substrates.

Inhibition by ornithine was tested for the enzymes listed in Table 2, except acetylornithinase. No inhibition could be detected for the first or the second biosynthetic enzymes, either in C. glutamicum or in recombinant E. coli cell extracts. The corynebacterial ornithine acetyltransferase activity was inhibited by ornithine (product inhibition); the apparent $K_{\mathrm{i}}$ value at saturating levels of substrates was $5 \mathrm{mM}$.

Fig. 3. Nucleotide sequence of the $4.4 \mathrm{~kb}$ DNA region of C. glutamicum ATCC 13032 with the predicted amino acid sequences encoded by the argCJBDF genes cluster. The potential ribosome-binding site (RBS) and selected restriction sites referred to in Fig. 2 are underlined. Stop codons are marked with asterisks. 
Table 2. Specific activities of four arginine biosynthetic enzymes in C. glutamicum and in E. coli strains carrying C. glutamicum arg genes

Values are the means of at least two measurements made on independent cultures. The values for replicate assays differed from the mean by $<20 \%$ for $N$-acetylglutamate synthase and ornithine acetyltransferase, and by $<10 \%$ for the other activities.

\begin{tabular}{|c|c|c|c|c|c|}
\hline \multirow[t]{2}{*}{ Strain } & \multirow{2}{*}{$\begin{array}{l}\text { Arginine } \\
\text { addition* }\end{array}$} & \multicolumn{4}{|c|}{ Specific activity [units (mg protein) ${ }^{-1}$ ] } \\
\hline & & $\begin{array}{c}N \text {-Acetylglutamate } \\
\text { synthase }\end{array}$ & $\begin{array}{c}N \text {-Acetylglutamate } \\
\text { kinase }\end{array}$ & $\begin{array}{c}\text { Ornithine } \\
\text { acetyltransferase }\end{array}$ & $\begin{array}{l}\text { Acetyl- } \\
\text { ornithinase }\end{array}$ \\
\hline C. glutamicum & - & 0.06 & $0 \cdot 10$ & $0 \cdot 16$ & ND \\
\hline \multicolumn{6}{|l|}{ ATCC 13032} \\
\hline & + & $0 \cdot 06$ & $0 \cdot 02$ & $0 \cdot 12$ & ND \\
\hline \multicolumn{6}{|l|}{ E. coli $\mathrm{K} 12$} \\
\hline XA4 & + & $<0.001$ & ND & $<0.001$ & ND \\
\hline $\mathrm{XA4}(\mathrm{pPP} 2)$ & + & $<0.001$ & ND & 0.36 & ND \\
\hline $\mathrm{XB} 25$ & + & ND & $<0.005$ & ND & ND \\
\hline $\mathrm{XB} 25(\mathrm{pPP} 2)$ & - & ND & $2 \cdot 1$ & ND & ND \\
\hline $\mathrm{XB} 25(\mathrm{pPP} 2)$ & + & ND & $2 \cdot 1$ & ND & ND \\
\hline $\mathrm{XB} 25(\mathrm{pKS}-1 \cdot 9)$ & - & ND & $2 \cdot 8$ & ND & ND \\
\hline $\mathrm{XB} 25(\mathrm{pKS}-1 \cdot 9)$ & + & ND & $1 \cdot 3$ & ND & ND \\
\hline $\mathrm{XB} 25(\mathrm{pGAB} 4)$ & - & ND & $2 \cdot 5$ & ND & ND \\
\hline XB25[pBluescript II KS(+)] & + & ND & $<0.005$ & ND & ND \\
\hline $\mathrm{XS1D} 2 \mathrm{R}$ & + & ND & ND & ND & $<0.001$ \\
\hline XS1D2R(pPP2) & - & ND & ND & ND & $<0 \cdot 001$ \\
\hline
\end{tabular}

ND, Not determined.

* Arginine was added to synthetic medium at a concentration of $5 \mathrm{mM}$. Succinate $(0.5 \%$, w/v) was added for E. coli XS1D2R strains. E. coli strains carrying plasmids were grown in the presence of ampicillin.

\section{Evolutionary relationships between enzymes of the acetyl cycle}

Comparison based on the Pearson \& Lipman algorithm (1988) fails to reveal any significant similarity between the sequences of $C$. glutamicum ornithine acetyltransferase and known $\mathrm{N}$-acetylglutamate synthases. This result enforces our earlier suspicion that in spite of their functional relatedness the $\arg A$ and $\arg J$ gene products belong to different evolutionary families (Sakanyan $e t$ al., 1993a).

FASTA comparisons (Pearson \& Lipman, 1988) with the registered polypeptide sequences do not point to any clear affiliation of the ornithine acetyltransferases. On the other hand similarities between the N-terminal part of ArgA and the $\operatorname{ArgB}$ polypeptide sequence have recently been noticed (Reith \& Munholland, 1993; Gessert et al., 1994). These similarities appear in fact most pronounced when E. coli $\mathrm{Arg} A$ and $C$.glutamicum $A \operatorname{rgB}$ amino acid sequences are compared: application of the Pearson \& Lipman (1988) RDF2 program establishes a similarity value that is 15 standard deviations above the mean value obtained with 100 random permutations of either sequence, a highly significant value. It may therefore be assumed that acetylglutamate synthases and kinases are indeed evolutionarily related.

An alignment of the known $\operatorname{Arg} A$ and $A \operatorname{rgB}$ polypeptide sequences (data not shown) indeed reveals several highly conserved amino acids. Surprisingly, no direct relatedness could be detected between the acetylglutamate synthase of N. crassa (Y. Yu \& R. L. Weiss; EMBL accession number L35484) and those of other organisms: the N. crassa ArgA enzyme seems weakly similar to kinase sequences only. The other known acetylglutamate synthase polypeptide sequences are obviously longer than the kinases by a stretch of about 100-140 amino acid residues, and some highly conserved regions occur in this part. The results of a FASTA search of the registered sequences in the SwissProt database suggests an intriguing affiliation. Indeed, a high similarity between this region of the E. coli acetylglutamate synthase and a 153 amino acid ORF, found next to the trpGDC cluster in Azospirillum (Zimmer et al., 1991), which in its turn can be related to the E. coli RimI enzyme that acetylates the $\mathrm{N}$-terminus of the ribosomal S18 gene (Yoshikawa et al., 1987) and the Streptomyces lavendulae StaT protein, an acetylCoA-dependent acetyltransferase (Horinouchi et al., 1987). The Azospirillum ORF is, moreover, highly similar to the E. coli $\mathrm{PhnO}$ protein (Makimo et al., 1991), which is involved in alkylphosphonate utilization that again appears related to various other acetyltransferases. These similitudes might reflect an ancient link between the $\arg A$-encoded enzyme C-terminal part and a family of small acetylCoAdependent acetyltransferases.

New insights into the function and the evolution of the acetyl cycle are presently being looked for in a comparative analysis of structure-function relationships 
in the monofunctional ornithine acetyltransferases of C. glutamicum disclosed in this work and the bifunctional, homologous enzyme of $B$. stearothermophilus (Sakanyan $e t$ al., 1993a).

\section{ACKNOWLEDGEMENTS}

We are indebted to D. Gigot for the synthesis of oligodeoxyribonucleotides. This work was partially supported by a Grant from the Région des Pays de la Loire (Contrat de Plan Etat-Région), by the Belgian Foundation for Fundamental and Joint Research (FRFC-FKFO), and by an OZR-fund of the Vrije Universiteit Brussel.

\section{REFERENCES}

An, G. \& Friesen, J. D. (1979). Plasmid vehicles for direct cloning of Escherichia coli promoters. J Bacteriol 140, 400-407.

Birnboim, H.C. \& Doly, J. (1979). A rapid alkaline extraction procedure for screening recombinant DNA. Nucleic Acids Res 7, 1513-1523.

Bolivar, F. (1978). Construction and characterization of new cloning vehicles. III. Derivatives of plasmid pBR322 carrying unique EcoRI sites for selection of EcoRI generated recombinant DNA molecules. Gene 4, 121-130.

Boonchird, C., Messengey, F. \& Dubois, S. (1991). Characterization of the yeast ARG5,6 gene: determination of the nucleotide sequence, analysis of the control region and of ARG5,6 transcript. Mol \& Gen Genet 226, 154-166.

Bröer, S., Eggeling, L. \& Krämer, R. (1993). Strains of Corynebacterium glutamicum with different lysine productivities may have different lysine excretion systems. Appl Environ Microbiol 59, 316-321.

Brown, K., Finch, P. W., Hickson, I. D. \& Emmerson, P. T. (1987). Complete nucleotide sequence of the Escherichia coli $\arg A$ gene. Nucleic Acids Res 15, 10586.

Cunin, R., Glansdorff, N., Pierard, A. \& Stalon, V. (1986). Biosynthesis and metabolism of arginine in bacteria. Microbiol Rev 50, 314-352.

Davis, R. H. (1986). Compartmental and regulatory mechanisms in the arginine pathways of Neurospora crassa and Saccharomyces cerevisiae. Microbiol Rev 50, 280-313.

Dharmsthiti, S. \& Krishnapillai, V. (1993). DNA sequence conservation at the gene level in a conserved chromosomal segment in two Pseudomonas species. $J$ Genet 72, 1-14.

Eikmanns, B. J., Kircher, M., Liebl, W. \& Reinscheid, D. J. (1991). Discrimination of Corynebacterium glutamicum, Brevibacterium flavum and Brevibacterium lactofermentum by restriction pattern analysis of DNA adjacent to the hom gene. FEMS Microbiol Lett 82, 203-208.

Gessert, S. F., Kim, J. H., Nargang, F. E. \& Weiss, R. L. (1994). A polyprotein precursor of two mitochondrial enzymes in Neurospora crassa. Gene structure and precursor processing. J Biol Chem 269, 8189-8203.

Haas, D. \& Leisinger, T. (1974). Multiple control of $N$ acetylglutamate synthetase from $P$ seudomonas aeruginosa: synergistic inhibition by acetylglutamate and polyamines. Biochem Biophys Res Commun 60, 42-47.

Haas, D. \& Leisinger, T. (1975). N-acetylglutamate 5phosphotransferase of Pseudomonas aeruginosa. Catalytic and regulatory properties. Eur J Biochem 52, 377-383.

Haas, D., Kurer, V. \& Leisinger, T. (1972). $N$-acetylglutamate synthetase of Pseudomonas aeruginosa. An assay in vitro and feedback inhibition by arginine. Eur J Biochem 31, 290-295.

Higgins, D. G. \& Sharp, P. M. (1988). Clustal: a package for performing multiple sequence alignment on a microcomputer. Gene 73, 237-244.

Hindle, Z., Callis, R., Dowden, S., Rudd, B. A. M. \& Baumberg, S. (1994). Cloning and expression in Escherichia coli of a Streptomyces coelicolor A3(2) argCJB gene cluster. Microbiology 140, 311-320.

Hoare, D. S. \& Hoare, S. L. (1966). Feedback regulation of arginine biosynthesis in blue-green algae and photosynthetic bacteria. $J$ Bacteriol 92, 375-379.

Horinouchi, S., Furuya, K., Nishiyama, M., Suzuki, H. \& Beppu, T. (1987). Nucleotide sequence of the streptothrycin acetyltransferase gene from Streptomyces lavendulae and its expression in heterologous hosts. J Bacteriol 169, 1929-1937.

Jones, D. \& Collins, M. D. (1986). Irregular, nonsporing Grampositive rods. In Bergey's Manual of Systematic Bacteriology, vol. 2, pp. 1261-1434. Edited by P. H. A. Sneath, N. S. Mair, M. E. Sharpe \& J. G. Holt. Baltimore: Williams \& Wilkins

Kinoshita, S. \& Nakayama, K. (1978). Amino acids. In Primary Products of Metabolism, pp. 209-261. Edited by A. H. Rose. London, New York \& San Francisco: Academic Press.

Makino, K., Kim, S., Shinagawa, H., Amemura, M. \& Nataka, A. (1991). Molecular analysis of the cryptic and functional $p h n$ operons for phosphonate use in Escherichia coli K-12. J Bacteriol 173, 2665-2672.

Malumbres, M., Gil, J. A. \& Martin, J. F. (1993). Codon preference in Corynebacteria. Gene 134, 15-24.

Martin, P. R. \& Mulks, M. H. (1992). Sequence analysis and complementation studies of the argJ gene encoding ornithine acetyltransferase from Neisseria gonorrboeae. J Bacteriol 174, 2694-2701.

Meile, L. \& Leisinger, T. (1984). Enzymes of arginine biosynthesis in methanogenic bacteria. Experientia 40, 899-900.

Miller, J. H. (1972). Experiments in Molecular Genetics. Cold Spring Harbor, NY: Cold Spring Harbor Laboratory.

Mountain, A., Mann, N. H., Munton, R. N. \& Baumberg, S. (1984). Cloning of a Bacillus subtilis restriction fragment complementing auxotrophic mutants of eight Eschericbia coli genes of arginine biosynthesis. Mol \& Gen Genet 197, 82-89.

Mountain, A., McChesney, J., Smith, M. C. M. \& Baumberg, S. (1986). Gene sequence encoding early enzymes of arginine synthesis within a cluster in Bacillus subtilis, as revealed by cloning in Escherichia coli. J Bacteriol 165, 1026-1028.

O'Reilly, M. \& Devine, K. M. (1994). Sequence and analysis of the citrulline biosynthetic operon $\arg C-F$ from Bacillus subtilis. Microbiology 140, 1023-1025.

Parsot, C., Boyen, A., Cohen, G. N. \& Glansdorff, N. (1988). Nucleotide sequence of Escherichia coli $\arg B$ and $\arg C$ genes: comparison of $N$-acetylglutamate kinase and $N$-acetylglutamate- $\gamma$ semialdehyde dehydrogenase with homologous and analogous enzymes. Gene 68, 275-283.

Pearson, W. R. \& Lipman, D. J. (1988). Improved tools for biological sequence comparison. Proc Natl Acad Sci USA 85, 2444-2448.

Picard, F. J. \& Dillon, J. R. (1989). Cloning and organization of seven arginine biosynthesis genes from Neisseria gonorrboeae. $J$ Bacteriol 171, 1644-1651.

Reith, M. \& Munholland, J. (1993). Two amino-acid biosynthetic genes are encoded on the plasmid genome of the red alga Porpbyra umbilicalis. Curr Genet 23, 59-65. 
Sakanyan, V. A., Hovsepyan, A. S., Mett, I. L., Kochikyan, A. V. \& Petrosyan, P. K. (1990). Molecular cloning and structural-functional analysis of the arginine biosynthesis genes of the thermophilic bacterium Bacillus stearothermophilus. Genetika 26, 1915-1925.

Sakanyan, V., Kochikyan, A., Mett, I., Legrain, C., Charlier, D., Piérard, A. \& Glansdorff, N. (1992). A re-examination of the pathway for ornithine biosynthesis in a thermophilic and two mesophilic Bacillus species. J Gen Microbiol 138, 125-130.

Sakanyan, V., Charlier, D., Legrain, C., Kochikyan, A., Mett, I., Piérard, A. \& Glansdorff, N. (1993a). Primary structure, partial purification and regulation of key enzymes of the acetyl cycle of arginine biosynthesis in Bacillus stearothermophilus: dual function of ornithine acetyltransferase. J Gen Microbiol 139, 393-402.

Sakanyan, V. A., Legrain, C., Charlier, D., Kochikyan, A. V., Osina, N. K. \& Glansdorff, N. (1993b). N-acetylglutamate-5-phosphotransferase of the thermophilic bacterium Bacillus stearothermopbilus: nucleotide sequence and enzyme characterization. Genetika 29, $556-570$

Sakanyan, V., Desmarez, L., Legrain, C., Charlier, D., Mett, I., Kochikyan, A. Savchenko, A., Boyen, A., Falmagne, P., Piérard, A. \& Glansdorff, N. (1993c). Gene cloning, sequence analysis, purification, and characterization of a thermostable aminoacylase from Bacillus stearothermophilus. Appl Environ Microbiol 59, 3878-3888.

Sambrook, J., Fritsch, E. F. \& Maniatis, T. (1989). Molecular Cloning: a Laboratory Manual, 2nd edn. Cold Spring Harbor, NY: Cold Spring Harbor Laboratory.

Sanger, F., Nicklen, S. \& Coulson, A. R. (1977). DNA sequencing with chain-terminating inhibitors. Proc Natl Acad Sci USA 74, 5463-5467.

Shiio, I., Otsuka, S. I. \& Takahashi, M. (1962). Effect of biotin on the bacterial formation of glutamic acid. I. Glutamate formation and cellular permeability of amino acids. $J$ Biochem 51, 56-62.

Shinners, E. N. \& Catlin, B. W. (1978). Arginine biosynthesis in Neisseria gonorrboeae: enzymes catalyzing the formation of ornithine and citrulline. J Bacteriol 136, 131-135.

Udaka, S. (1966). Pathway-specific pattern of control of arginine biosynthesis in bacteria. J Bacteriol 91, 617-621.
Udaka, S. \& Kinoshita S. (1958). Studies on L-ornithine fermentation. I. The biosynthetic pathway of L-ornithine in Micrococcus glutamicus. J Gen Appl Microbiol 4, 272-282.

Van de Casteele, M., Demarez, M., Legrain, C., Glansdorff, N. \& Piérard, A. (1990). Pathways of arginine biosynthesis in extreme thermophilic archaeo- and eubacteria. J Gen Microbiol 136, $1177-1183$.

Van Huffel, C., Dubois, E. \& Messenguy, F. (1992). Cloning and sequencing of $\arg 3$ and $\arg 11$ genes of Scbizosaccharomyces pombe on a $10-\mathrm{kb}$ DNA fragment. Heterologous expression and mitochondrial targeting of their translation products. Eur $J$ Biochem 205, 33-43.

Vieira, J. \& Messing, J. (1982). The pUC plasmids, a M13mp7derived system for insertion mutagenesis and sequencing with synthetic universal primers. Gene 19, 259-268.

Vogel, H. J. \& MacLellan, W. L. (1970). Acetylornithinase (E. coli). Methods Enzymol 17A, 265-269.

Wipf, B. \& Leisinger, T. (1979). Regulation of activity and synthesis of $N$-acetylglutamate synthase from Saccharomyces cerevisiae. J Bacteriol 140, 874-880.

Yamada, K. \& Komagata K. (1970). Taxonomic studies on coryneform bacteria. III. DNA base composition of coryneform bacteria. J Gen Appl Microbiol 16, 55-65.

Yanisch-Perron, C., Vieira, J. \& Messing, J. (1985). Improved M13 phage cloning vectors and host strains : nucleotide sequences of the M13mp18 and pUC19 vectors. Gene 33, 103-119.

Yoshikawa A., Isono, S., Sheback, A. \& Isono, K. (1987). Cloning and nucleotide sequencing of the genes $\mathrm{rimI}$ and $\mathrm{rim} J$ which encode enzymes acetylating ribosomal proteins $\mathrm{S} 18$ and S5 of Escherichia coli. Mol \& Gen Genet 209, 481-488.

Zimmer, W., Aparicio, C. \& Elmerich, C. (1991). Relationship between tryptophan biosynthesis and indole-3-acetic acid production in Azospirillum: identification and sequencing of a $\operatorname{trp} G D C$ cluster. Mol E Gen Genet 229, 41-51.

Received 1 August 1995; accepted 25 August 1995. 